\title{
Allergy and infant feeding
}

\section{By J. F. Soothill, Department of Immunology, Institute of Child Health, 30 Guilford Street, London $W C_{1} N$ I $E H$}

Allergy to food, whether mediated by immunoglobulin $\mathrm{E}$, immunoglobulin $\mathrm{G}$ and complement, or by cell-mediated responses, may cause a wide range of symptoms, local (vomiting, diarrhoea and failure to thrive), or general (eczema, asthma, sudden death). In infancy cow's milk is the predominant allergen, but many foods may be involved.

In each instance, a normal immunity mechanism is overstimulated by antigen, to cause trouble. Such allergies are common in grossly immunodeficient children, suggesting that the damaging system is overstimulated because another system has failed to eliminate or exclude the antigen. Can such relative deficiency occur within the normal range, to explain other allergy ( $16 \%$ of British children)? The following functions vary within the normal range, with poor function leading to poor elimination or exclusion of antigen, or to allergy, or to both.

Antigen specific:

Tissue type

Frequency

(\%) Treatment

Antigen non-specific:

Low-affinity antibody

Macrophage function

Transient immunoglobulin A deficiency

Defective alternative pathway of complement

Heterozygosity for cystic fibrosis

$\begin{array}{ll}r & \text { None } \\ \text { ?>IO } & \begin{array}{l}\text { Adjuvant immunization, antibody, } \\ \text { nutrition }\end{array} \\ \text { ?>10 } & \text { Nutrition } \\ \text { ?>IO } & \text { Neonatal antigen avoidance } \\ \text { c. } 5 & \text { Neonatal antigen avoidance? } \\ \text { c. } 5 & \text { None }\end{array}$

Affinity of antibody, and macrophage function, are strongly influenced by dietary protein, as are other immunity functions. Transient immunoglobulin A (IgA) deficiency precedes the development of eczema and positive prick tests, in infants of allergic parents. Allergen avoidance, including breast-feeding, prevents the development of eczema in these infants. This may work by simple antigen avoidance, but different foods have profoundly different effects on the establishment of the gut flora, which might also lead to different vulnerability to allergy in the child with IgA deficiency, or of the defect of the alternative pathway of complement.

This work suggests that variation of immunity function within the normal range is relevant for vulnerability to infection and allergy. Therefore the fact that most infants can be artificially fed without considerable loss (as happens in most species) does not mean that all can. The type of damage we have shown to follow adverse antigen experience in the neonatal period, in the child with special genetically 
determined susceptibility may well be associated with many other more lasting diseases.

Reviews dealing more fully with this subject have recently appeared (Soothill, $1976 a, b)$.

\section{REFERENCES}

Soothill, J. F. (1976a). Immunodeficiency, Allergy and Infant Feeding. Symposia of the Swedish Nutrition Foundation, no. 13 [G. Blix, editor]. Uppsala: Almquist \& Wiksells.

Soothill, J. F. (1976b) Proc. R. Soc. Med. 69, 439. 